\title{
Life Cycle Thinking for Sustainable Consumption and Production towards a Circular Economy
}

\author{
Shabbir H. Gheewala ${ }^{1,2^{*}}$ \\ ${ }^{1}$ The Joint Graduate School of Energy and Environment, King Mongkut's University of Technology \\ Thonburi, 126 Prachauthit, Bangmod, Tungkru, Bangkok 10140, Thailand \\ ${ }^{2}$ Center of Excellence on Energy Technology and Environment, PERDO, Ministry of Higher \\ Education, Science, Research and Innovation, Bangkok, Thailand
}

\begin{abstract}
The current model of a linear economy with end-of-pipe waste treatment is not sustainable. Cleaner production helps reduce resource use and emissions, but is still not an optimal solution without considering a life cycle perspective. Life cycle-based tools such as life cycle assessment and life cycle costing are useful for identifying optimal environmental and economic options for product systems. SDG 12 dealing with responsible consumption and production is key for sustainability. Developing of a circular economy requires life cycle thinking and life cycle-based tools for assessment. All these issues are discussed along with illustrative examples.
\end{abstract}

\section{Introduction}

Every activity is associated with some consequences; the desired objective of the activity usually leading to some benefit to society but also with some undesired outcomes which are unplanned, but inevitable. In practice, thermodynamics does not allow us to break even and we will end up losing some utility whenever there is an activity or transformation. Activities in nature must also follow this law, but a decrease in entropy is powered by energy from the sun. Activities in nature are part of ecosystems, large and small, which are very delicately but efficiently balanced in a way that there is no waste per se. All elements/substances move in cycles which is, for example, easily evident in the hydrological cycle which represents the cyclic movement of water on earth. There are many such biogeochemical cycles for nitrogen, sulphur and so on. Industrial activities, on the other hand, have largely been developed in a linear format - so called take, make, use and dispose (Figure 1). We take valuable resources from nature, transform them to products which are then used and finally go back to nature in the form of waste - solid, liquid or gaseous. The loop is not "closed". Hence, every activity must somehow lead to some form of pollution being produced.

* Corresponding author: shabbir_g@jgsee.kmutt.ac.th; shabbirg@hotmail.com 


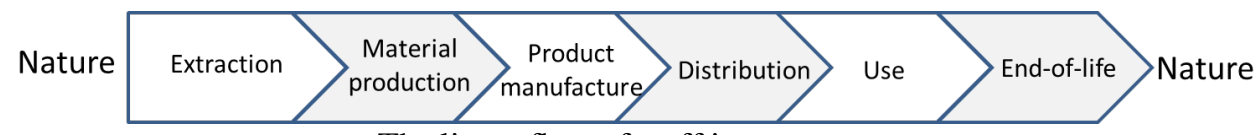

Fig. 1. The linear flow of stuff in our economy.

When these anthropogenic activities were at a rather small scale, the impact of pollution from the production and disposal activities was not very visible, partly due to dilution and also due to the ability of nature to absorb and transform the waste into benign products that once again entered the natural cycles. This is the so-called carrying capacity of the earth. However, with the beginning of industrialization, the pollution arising from industrial activities started to increase to levels that were beyond the carrying capacity of the earth both in terms of the volume of pollution being produced and also the type of pollution (e.g. xenobiotics) which was difficult to be transformed by nature into relatively benign forms. Dilution is no more the solution to pollution. Thus, the need for treating the pollution was recognized and institutionalized into laws and regulations on waste treatment or pollution abatement. From the producers' point of view, however, waste treatment, also called "end-of-pipe" treatment, is an unproductive activity as investment must be made for it without having any financial returns. This is not attractive to the producers and must be enforced through regulations.

To address this issue in a smarter way, we need to take a look at the production process in details. Let us consider a generic production process (Figure 2a). To produce an output (product), raw materials and energy are provided to a production process. Thermodynamics dictates that there will inevitably be some waste production; this undesired output (waste) is also from a part of the raw materials and energy entering the production process. In the conventional way of dealing with waste, we must resort to end-of-pipe treatment where we must invest some more raw materials and energy (and of course money) to "manage" the waste. However, if we can focus on reducing this waste stream by improving the process in some way, then we have a double benefit. First of all, we can either increase the amount of product with the same amount of raw materials and energy (Figure 2b) or decrease the amount of raw materials and energy input to produce the same amount of product (Figure 2c). Secondly, the less waste produced means we need to treat less waste. This is the basic concept of cleaner production.
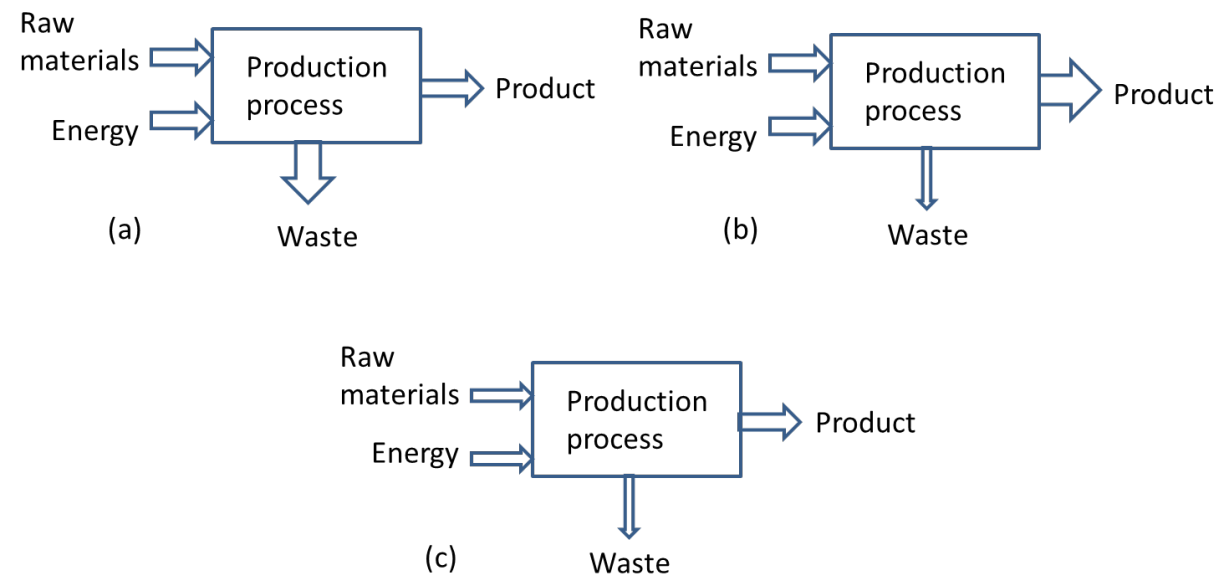

Fig. 2. Generic production process (a) conventional production (b), (c) cleaner production. 
Cleaner production thus focuses on reducing the use of raw materials and energy as well as the production of emissions and waste (Figure 3). This idea is very appealing to the industry as it reduces the unproductive activity of waste management and is associated with financial benefits as well. Cleaner production initially focused on a particular production process or a factory. However, this focus, though beneficial, is still limited because it may result in problem shifting as will be seen below.

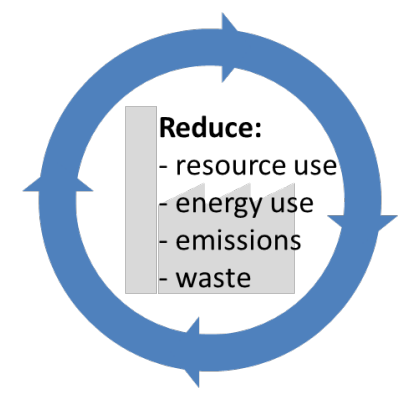

Fig. 3. The concept of cleaner production.

\section{Life cycle thinking}

Among the many examples of problem shifting that can be observed in practice, one of the currently relevant ones is that of electric vehicles, i.e. cars that are powered by electricity. These vehicles are being promoted especially in cities with a high level of vehicular pollution from conventional cars. Conventional cars are usually fuelled by gasoline, diesel, compressed natural gas or liquefied natural gas. These cars emit pollutants when the above fuels are combusted in the engine to provide motive power. The pollution is quite "obvious" as can be observed physically when emitted from the tail pipe of the car. However, electricity cars run on electricity stored in batteries; thus these cars do not even need a tail pipe and produce no polluting emissions at the car level. So a very direct comparison focused on the car itself would yield a straightforward answer that electric cars are less polluting than their conventional counterparts. However, when we extend the scope of the study beyond the car itself, we immediately realize that even though there is no pollution from powering the electric car itself, there is in fact pollution during the production of electricity used to power the cars. In fact, depending on the fuel used to produce the electricity, the efficiency of the power plant and transmission losses, the amount of pollutant emissions at the power plant can be very high. This leads to the idea of looking at the entire life cycle of the car to avoid missing out on the problem shifting, i.e. the pollutant emissions being transferred from the car itself to the power plant (Figure 4). 

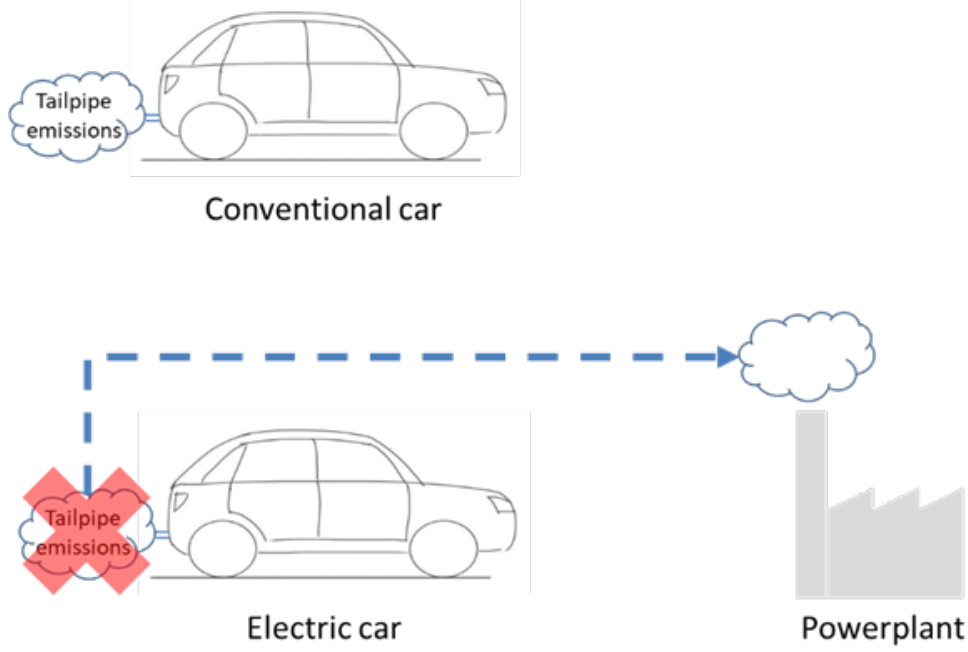

Fig. 4. Conventional and electric cars.

So it is quite clear that when making a comparison between conventional and electric cars, it would not be enough to focus only on the car, but also look at the fuel used to provide motive power. In fact, it would be even more appropriate to look at the entire life cycle which in this case would actually include two life cycles (Figure 5) - one of the car itself (resource extraction, materials manufacturing, components manufacturing, vehicle assembly, use and disposal at the end-of-life along with all the intermediate transportation) and that of the energy carrier (energy resource extraction, as well as production, distribution, storage, conversion and transmission of the energy carrier). So even before the car travels the first kilometer, it has already accumulated environmental impacts (called "embodied impacts") from the production stage. When the car is used, additional impacts accrue from the fuel cycle as also the maintenance of the car. At the end of life, there will be impacts from the disposal of the car (parts of it may be recycled, or disposed of by other means such as landfilling and incineration). Since the life of the car is usually quite long (maybe to the order of 10-20 years), the impacts during the use phase can be quite decisive, but anyway, not the only ones as explained above.

To make a fair environmental comparison between alternative cars, a life cycle assessment (LCA) considering the environmental burdens generated at each stage of both the car and energy carrier life cycles must be considered. This will avoid the issue of problem shifting that would occur should the system boundary be focused only on the use of the car itself. 


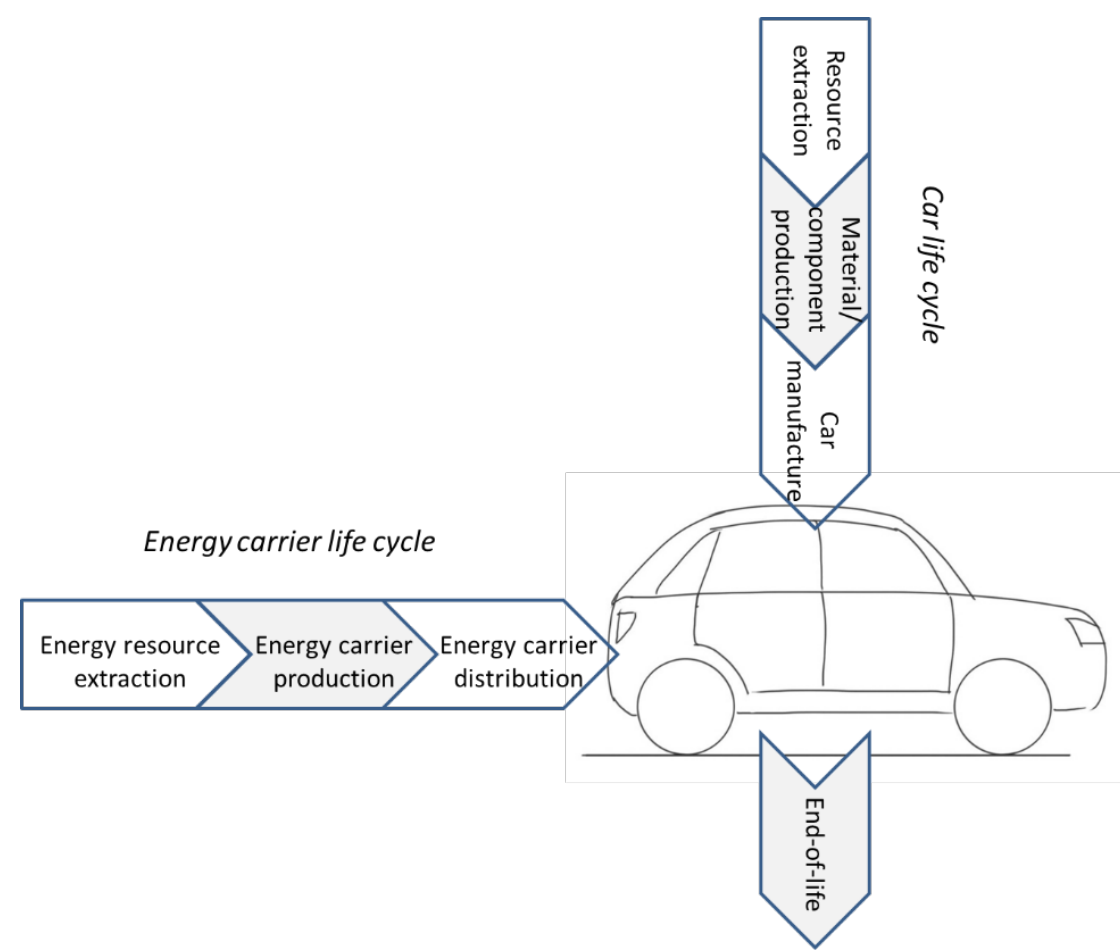

Fig. 5. Generic system boundary for assessment of cars (Adapted from [1]).

The concept of life cycle thinking is applied not only to environmental assessments via tools such as LCA, but is also applied to the other pillars of sustainability, such as life cycle costing (LCC) for economic assessment and social life cycle assessment (S-LCA) for social assessments. The utility of a life cycle approach for economic assessment is illustrated by a simple example of light bulbs. Let us consider three commonly available light bulbs - the traditional incandescent bulb, the more advanced compact fluorescent light (CFL) and the even more advanced light emitting diode (LED). The prices of one bulb of each kind (for similar amount of lighting) are 1 USD, 2 USD and 8 USD for the incandescent, CFL and LED respectively. If for lighting our house, we were to make a choice between these three options based on the purchasing price, one should obviously choose the incandescently bulb. However, would it be a wise choice to make the decision based only on the price paid upfront for purchasing the bulb? Now that we have seen the effect of life cycle thinking in the environmental comparison of cars, let us try to use a similar approach for decision-making here as well. The results of the LCC are presented in Table 1.

Table 1. Life cycle costing of incandescent, CFL and LED light bulbs.

\begin{tabular}{|l|l|l|l|}
\hline & Incandescent & CFL & LED \\
\hline Cost per bulb (upfront) & $1 \mathrm{USD}$ & $2 \mathrm{USD}$ & $8 \mathrm{USD}$ \\
\hline Average lifespan & $1,200 \mathrm{~h}$ & $8,000 \mathrm{~h}$ & $25,000 \mathrm{~h}$ \\
\hline Power & $60 \mathrm{~W}$ & $14 \mathrm{~W}$ & $10 \mathrm{~W}$ \\
\hline Number of bulbs for 25,000 h & 21 & 3 & 1 \\
\hline Total purchase price & $21 \mathrm{USD}$ & $6 \mathrm{USD}$ & 8 USD \\
\hline Total cost of electricity (@ $0.12 \mathrm{USD} / \mathrm{kWh})$ & $180 \mathrm{USD}$ & $42 \mathrm{USD}$ & 30 USD \\
\hline Life cycle costing & $\mathbf{2 0 1}$ USD & $\mathbf{4 8}$ USD & 38 USD \\
\hline
\end{tabular}


It can be seen that there are several other important issues to consider in addition to the purchasing price of the bulb. One is the average lifespan of each bulb which differs quite significantly across the three bulbs. The other is the power consumption of the bulbs to provide the same amount of illumination which is very different; the CFL and LED are far more energy efficient than the incandescent bulb. When all these factors are considered to calculate the LCC, the LED becomes the cheapest option among the three even though the price paid upfront was the highest. Thus, it is clear that considering the LCC will yield the more sensible result since it accounts for all the costs the user has to ultimately pay for using the bulb.

\section{Sustainable Consumption and Production}

SDG 12 deals with responsible consumption and production; which is directly aligned with sustainable consumption and production. The example of the electric car that was used above was from the point of view of sustainable production. Sustainable consumption can be from the point of view of the consumer or user who must make an informed choice based on environmental considerations. The example of the light bulb above, though focused on economics, could also be considered as sustainable consumption in terms of environment if we focus on the electricity use of the bulbs. Both sustainable production and sustainable consumption must go hand in hand; producers produce sustainably and consumers consume sustainably. Sometimes a chicken and egg situation may evolve where the producers may claim that they will produce sustainably if there is a demand (price premium) for environmentally friendly products whereas consumers may claim that they will buy environmentally friendly products if these are easily accessible. Environmental labels or ecolabels may help to bridge this gap by providing environmental information to consumers who could then make a conscious choice. Of course consumers may not make a choice based on environmental considerations alone - brand, price, other characteristics (e.g. nutrition for food products) may also play a significant role. If ecolabels can be combined also with life cycle costing information, then it makes much sense for the consumer. For example, electricity using products in Thailand such as refrigerators, televisions, washing machines, fans, air conditioners, etc. often carry a No. 5 label which shows the electricity consumption of a product as compared to a threshold benchmark. Such a label also shows the price paid for electricity during the use phase. This sends a very clear message to the consumers who really appreciate this information; the No. 5 label became much more visible and well-known in Thailand than the green label which has been in existence for much longer (Figure 6). Here, it must be pointed out that in some way, both these labels involve life cycle thinking; the green label's criteria are based on life cycle considerations and the No. 5 label is based on the idea of life cycle costing, including the cost of operating the product in addition to the purchasing price of the product. 


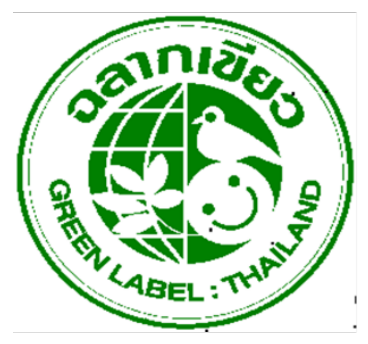

(a)

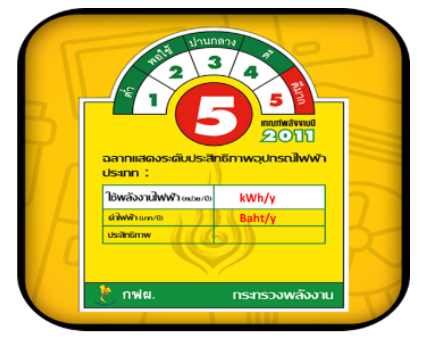

(b)

Fig. 6. Labels in Thailand (a) Green label (b) No. 5 label.

The government can facilitate the promotion of green labels by providing support to organizations that manage these labels as well as by introducing green product procurement schemes whereby organizations are encouraged to purchase products with certain ecolabels. This has been practiced in many countries such as Japan, South Korea and Thailand. Sustainable consumption is not limited to the purchase of products with ecolabels but also involves deeper changes in thinking and lifestyle. Reducing overconsumption and waste are very powerful considerations without which efficiency improvements alone cannot succeed in reducing overall environmental impacts.

\section{Circular Economy}

The concept of circular economy tends to move beyond products and look at the industry and even the society at large in trying to reduce resource and energy use. As the name suggests, the philosophy of circular economy is to move away from the "take, make, use and dispose" pathway of a linear economy and towards "closing the loop" (Figure 7). It goes much beyond cleaner production which is focused on reducing resource and energy use, and emissions and waste generated at each life cycle stage. These reductions, though desirable, are still not enough. At the lowest level of closing the loop is materials recycling. Although materials recycling is usually considered very good in terms of its environmental advantages, it is considered at the lowest level for the circular economy because all the resources and energy invested into making the component/product whose materials are recycled, are lost. Anyway, it is better than dumping the materials into a landfill or incinerating. However, much better would be if the component/product could be repaired, refurbished, remanufactured and ultimately reused as a new component/product. 


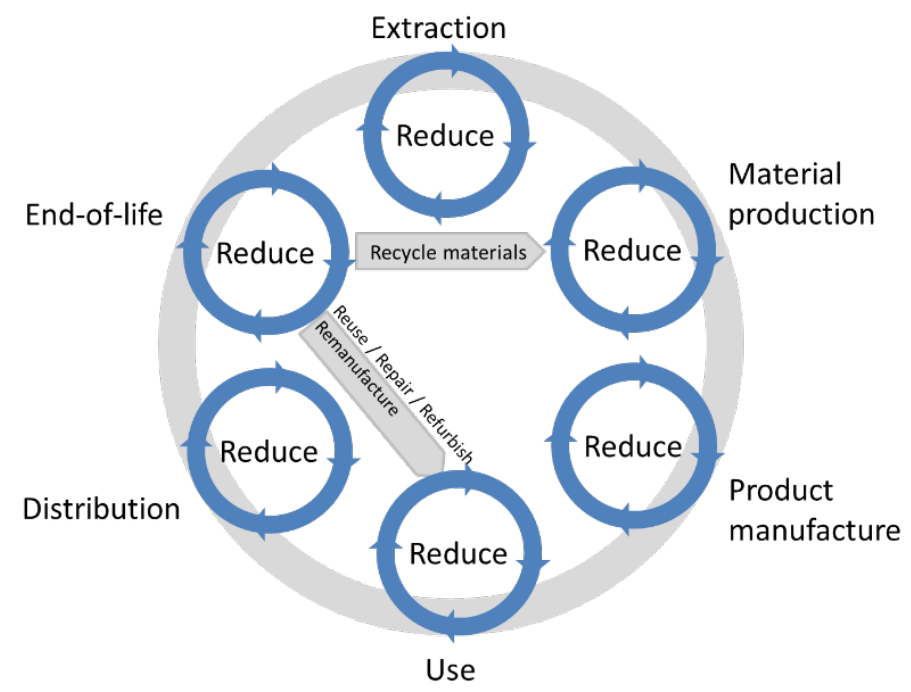

Fig. 7. The circular economy concept.

To facilitate repair, refurbishing and remanufacturing at a systematic and organized level, however, requires a shift in the business philosophy [2]. In the conventional business model, the ownership of a product is transferred from the producer to the consumer at the point of sale. Once, the product is purchased by the consumer, the producer is no longer responsible for it except maybe for a service contract during the warranty period. How the product is used and later disposed of is then the responsibility of the consumer/user. However, reusing after repair, refurbishing and remanufacturing would require a shift in the business model where the ownership of the product does not stay with the user either at the end of life of the product (extended producer responsibility) or never leaves the producer at all (leasing of the product or selling of the product service to the consumer rather than selling the product itself). The producer of the product then designs the product in such a way that it can be easily disassembled, repaired, components replaced, upgraded, or at least the materials recycled as a last option.

Here too, life cycle thinking and life cycle-based tools are essential. To illustrate this with a very simple example of recycling; materials such as aluminium which require a very large amount of energy for virgin production from bauxite as compared to the energy used for remelting during recycling will have a clear advantage when looked at from a life cycle perspective. However, other materials such as glass where there is a more modest difference between virgin production from sand and recycling by remelting will have to be looked at more cautiously. Should the impacts from transportation be quite significant due to long distances, the benefits from recycling may not necessarily be attractive when looked at from a life cycle perspective. Applying LCA and LCC would reveal these issues. Such considerations would also be useful for assessing the other examples mentioned above vis-àvis the circular economy. A careful and rigorous analysis using such tools should be conducted to support decision making as well as to identify hotspots and options to mitigate both the environmental and economic costs. 


\section{References}

1. F. Cerdas, P. Egede, C. Herrmann. LCA of Electromobility. In Hauschild et al. (eds.), Life Cycle Assessment, Springer International Publishing AG (2018)

2. W.R. Stahel. The Circular Economy: A User's Guide, Routledge (2019) 